\title{
Cytotoxic Escherichia coli strains encoding colibactin and cytotoxic necrotizing factor (CNF) colonize laboratory macaques
}

Yan Feng ${ }^{1 \dagger}$, Anthony Mannion ${ }^{1 \dagger}$, Carolyn M. Madden ${ }^{1}$, Alton G. Swennes ${ }^{1,2}$, Catherine Townes ${ }^{1}$, Charles Byrd ${ }^{1,3}$, Robert P. Marini ${ }^{1}$ and James G. Fox ${ }^{1 *}$

\begin{abstract}
Background: Many Escherichia coli strains are considered to be a component of the normal flora found in the human and animal intestinal tracts. While most E. coli strains are commensal, some strains encode virulence factors that enable the bacteria to cause intestinal and extra-intestinal clinically-relevant infections. Colibactin, encoded by a genomic island ( $p k s$ island), and cytotoxic necrotizing factor (CNF), encoded by the cnf gene, are genotoxic and can modulate cellular differentiation, apoptosis and proliferation. Some commensal and pathogenic pks+ and cnf + E. coli strains have been associated with inflammation and cancer in humans and animals.

Results: In the present study, E. coli strains encoding colibactin and CNF were identified in macaque samples. We performed bacterial cultures utilizing rectal swabs and extra-intestinal samples from clinically normal macaques. A total of 239 E. coli strains were isolated from 266 macaques. The strains were identified biochemically and selected isolates were serotyped as O88: $\mathrm{H} 4, \mathrm{O} 25: \mathrm{H} 4, \mathrm{O} 7: \mathrm{H7}$, OM:H14, and OM:H16. Specific PCR for pks and cnf1 gene amplification, and phylogenetic group identification were performed on all E. coli strains. Among the 239 isolates, 41 (17.2\%) were $p k s+/ c n f 1-, 19$ (7.9\%) were $p k s-/ c n f 1+$, and 31 (13.0\%) were $p k s+/ c n f 1+$. One hundred forty-eight (61.9\%) $E$. coli isolates were negative for both genes ( $p k s-/ c n f 1-)$. In total, 72 (30.1\%) were positive for pks genes, and 50 (20.9\%) were positive for $\mathrm{cnf1}$. No cnf2+ isolates were detected. Both pks+ and cnf1+E. coli strains belonged mainly to phylogenetic group B2, including B2 2 . Colibactin and CNF cytotoxic activities were observed using a HeLa cell cytotoxicity assay in representative isolates. Whole genome sequencing of 10 representative E. coli strains confirmed the presence of virulence factors and antibiotic resistance genes in rhesus macaque E. coli isolates.
\end{abstract}

Conclusions: Our findings indicate that colibactin- and CNF-encoding E. coli colonize laboratory macaques and can potentially cause clinical and subclinical diseases that impact macaque models.

\section{Background}

Escherichia coli is the predominant aero-anaerobic Gramnegative species of the normal microflora colonizing the gastrointestinal tract of humans and animals [1]. Most E. coli strains are commensal and rarely cause clinicallyrelevant disease. However, some strains carry virulence

\footnotetext{
*Correspondence: jgfox@mit.edu

†Yan Feng and Anthony Mannion are co-first authors

${ }^{1}$ Division of Comparative Medicine, Massachusetts Institute

of Technology, 77 Massachusetts Avenue, 16-825, Cambridge, MA 02139,

USA

Full list of author information is available at the end of the article
}

genes that enable selected $E$. coli strains to cause intestinal and extra-intestinal infections [2, 3]. Based on a phylogenetic assay, E. coli can be classified into four main phylogenetic groups (A, B1, B2 and D) [4-7]. Pathogenic strains which often encode virulence factors belong to group $\mathrm{B} 2$ and D, while most fecal E. coli strains belonging to group A and B1 lack virulence factors [8, 9]. A group of cytotoxins, including colibactin, cytotoxic necrotizing factors (CNFs), cytolethal distending toxin (CDT) and cycle inhibiting factor (CIF), are classified as cyclomodulins and are genotoxic and/or modulate cellular differentiation, apoptosis and proliferation [10-12]. 
Colibactin is a cytotoxic hybrid polyketide/nonribosomal peptide produced by several species of Enterobacteriaceae. It was first identified in 2006 in an extra-intestinal pathogenic E. coli (ExPEC) strain isolated from a case of neonatal meningitis [12]. This secondary metabolite, colibactin, is produced by the $c l b A-S$ genes present in the 54-kb pathogenicity $p k s$ island, a genetic island encoding a non-ribosomal peptide synthetase-polyketide synthase (NRPS-PKS) assembly line $[12,13]$. In vitro studies have shown that $p k s+E$. coli strains induce enlargement of cells and nuclei without mitosis (megalocytosis), cause G2 cell cycle arrest, and DNA double strand breaks [12]. In animal model experiments, a pks+E. coli strain (NC101), isolated from specific pathogen free wild-type mice induced inflammation in the cecum in interleukin 10 knockout $\left(\mathrm{IL} 10^{-/-}\right.$) mice after a 3 week monoassociation period [14]. Studies also demonstrated that monoassociation with NC101 promotes invasive carcinoma in $\mathrm{IL}_{10}{ }^{-/-}$ mice treated with azoxymethane (AOM). The promotion effect was dependent on expression of the $p k s$ island [15]. In a previous study from our laboratory, $88 \%$ of $E$. coli isolates from laboratory mice encoded $p k s$ genes and belonged to phylogenetic group B2 [16]. Our findings indicated that colibactin-encoding E. coli commonly colonize laboratory mice and may induce clinical and subclinical disease that may impact in vivo experimental results [16].

Escherichia coli strains that produce CNF belong to the pathotype necrotoxigenic E. coli (NTEC) and are associated with intestinal and extra-intestinal infection in both humans and animals [2]. The majority of CNFs include chromosomally encoded cnf1 [17] and plasmid-encoded cnf2 [18]. CNF1 is a $115 \mathrm{kDa}$ protein toxin which activates Rho GTPases, leading to cytoskeletal and cell cycle alterations with subsequent macropinocytosis and formation of megalocytic, multinucleated cells. CNF1-producing and $\beta$-hemolytic E. coli strains most notably cause urinary tract and meningeal infections in humans [19]. These strains are also isolated from healthy and diseased animals. In our laboratory, $c n f 1+E$. coli strains were isolated from ferrets with diarrhea and extra-intestinal infections [20] and from healthy macaques [21]. cnf1-encoding $E$. coli strains have also been isolated from cats [22], dogs [23, 24], pigs [25], and birds [26].

The prevalence of $p k s+E$. coli in rhesus macaques is not known, nor is there published evidence that $E$. coli strains encoding both $p k s$ and $c n f$ genes colonize macaques. The purpose of the present study was to characterize rectal $E$. coli isolates, as well as extra-intestinal isolates, from macaques for the presence of specific virulence genes ( $p k s$ and $c n f$ ) and demonstrate their in vitro toxin activities.

\section{Methods}

\section{Animals}

Macaques (Macaca mulatta and M. fascicularis), originally received from three US-based vendors, received physical examinations and routine diagnostic evaluations during quarantine and at quarterly intervals in 2012, 2014 and 2016. The colony contained 84 animals in 2012 (4 cynomolgus macaques and 80 rhesus macaques, of which 23 were female), 85 animals in 2014 (4 cynomolgus macaques and 81 rhesus macaques, of which 24 were female) and 97 animals in 2016 ( 2 cynomolgus macaques and 95 rhesus macaques, of which 25 were female). They ranged in age from 4 to 20 years. Animals were routinely pair-housed and maintained in an animal facility accredited by the Association for Assessment and Accreditation of Laboratory Animal Care (AAALAC) International. They were fed specified amounts of primate chow (Purina Lab Diet 5038) twice a day and supplemented daily with treats, seasonal fruits and vegetables. Water was provided ad libitum when animals were not on studies requiring water regulation. Housing conditions were maintained at $20-22{ }^{\circ} \mathrm{C}, 30-70 \%$ humidity, $10-15$ non-recirculated air changes per hour and a light cycle of $12 \mathrm{~h}$ light: $12 \mathrm{~h}$ dark.

\section{Microbiological analysis Culture and isolation}

Two hundred and sixty-nine samples (265 rectal swab, one gingival, two from cephalic recording chambers and one from margin skin) were collected from a cohort of 266 clinically normal macaques (those received in quarantine as well as the established cohort of macaques actively being used in neurobiological research) during quarterly colony health examinations in $2012(\mathrm{n}=84)$, $2014(\mathrm{n}=85)$ and $2016(\mathrm{n}=97)$. Rectal swabs were placed in tubes with sterile Gram-negative broth (BD) and incubated aerobically overnight at $37{ }^{\circ} \mathrm{C}$. The next day, a sterile swab was placed in the Gram-negative culture tube and then streaked onto MacConkey lactose agar plates (BD/BBL, Sparks, MD). For extraintestinal samples, the swab were placed in sterile trypticase soy broth (TSB) (BBL) and incubated aerobically overnight at $37^{\circ} \mathrm{C}$. The next day, a sterile swab was placed in the TSB culture tube and streaked onto Chocolate agar (BBL) and a split plate of blood agar with sheep blood and MacConkey agar (BBL). Lactose-positive colonies were selected and plated onto a sheep blood agar plate (Remel, Lenexa, KS), incubated aerobically, and $\beta$-hemolysis, if present, was noted. Suspect $E$. coli isolates were then characterized by analytic profile index (API) $20 \mathrm{E}$ (Biomérieux, Cambridge, MA). API $20 \mathrm{E}$ is a panel of biochemical tests used for the identification and differentiation of enteric Gram-negative rods. A profile number, determined by the sequence of positive and negative test reactions, is 
referenced in the API codebook database to determine the bacterial species. Swabs from cranial implants were placed in sterile TSB (BBL), used as an enrichment broth. The swabs were then plated onto chocolate agar (BBL) and a split plate of blood agar with sheep blood and MacConkey agar (BBL). Colonies that were lactose-fermenting positive and Gram-negative on Gram's stain were subcultured onto sheep blood agar and identification was confirmed with the API 20 E (Biomérieux).

\section{Clinical correlation}

Medical records were evaluated for temporal correlations of culture and clinical signs from animals which had $p k s+$ or $p k s / c n f 1$ double-positive E. coli isolates. Four records (3 for 2012 and 1 for 2014) were unavailable.

\section{DNA extraction, PCR amplification, and sequencing}

Escherichia coli colonies grown on blood agar plates were collected in sterile phosphate buffered saline (PBS) in microfuge tubes, boiled for $10 \mathrm{~min}$, followed by centrifugation at $12,000 \mathrm{~g}$ for $10 \mathrm{~min}$. The supernatant was used for PCR analysis. The primers and annealing temperatures used are shown in Additional file 1: Table S1. To detect the colibactin genes, three sets of primers were used to amplify $c l b A, c l b B$ and $c l b Q$ genes. Multiplex $c n f$ primers were used to screen for the $c n f$ gene followed by PCR with $\operatorname{cnf} 1$ and $\operatorname{cnf} 2$ specific primers to further distinguish $c n f$ subgroups. Selected strains were assayed for $c d t$ and cif using primers listed in Additional file 1: Table S1. To determine the phylogenetic groups of isolates, five sets of primers for the genes yjaA, TspE4.C2, chuA, svg and uidA were used in a multiplex PCR $[4,7]$. The phylogenetic groups were determined based on the PCR gel pattern. Sequencing of $16 \mathrm{~S}$ rRNA and $c l b A$ and $c l b Q$ genes was performed at QuintaraBio (Allston, MA) using primers 9F and F16 (16s rRNA), IHAPJPN42 and IHAPJPN46 (clbA), IHAPJPN55 and IHAPJPN56 (clbQ) for selected isolates.

\section{Serotyping}

Eleven $E$. coli isolates chosen from different cohorts and representing $p k s+/ c n f 1-, p k s-/ c n f 1+, p k s+/ c n f 1+$, and $p k s-/ c n f 1$ - genotypes were submitted to the E. coli Reference Center at Penn State University for serotype testing, which included: $\mathrm{O}$ and $\mathrm{H}$ typing and $\mathrm{PCR}$ analyses for heat-labile enterotoxin (elt), heat-stabile enterotoxin (est $A$ and estB), Shiga-type toxin 1 and 2 (Stx 1 and Stx 2 ), intimin gamma (eae), cnf1, and cnf2.

\section{Cytotoxicity assay}

Escherichia coli strains screened in the cytotoxicity assay included K12 (negative control), V27 (a $p k s$ and $c d t$ positive control acquired from the E. coli Reference Center), NC101 and NC101 $\Delta p k s$ (a pks positive control and $p k s$ mutant strain, respectively, both gifts from Dr. Christian Jobin), and 12 selected $E$. coli isolates representing $p k s+/ c n f 1-, p k s-/ c n f 1+, p k s+/ c n f 1+$, and $p k s-/ c n f 1-$ genotypes (three for each genotype). Selected tests were also performed on the E. coli strains used in the cytotoxicity assays and included: API $20 \mathrm{E}$ for biochemical characterization and PCR for phylogenetic groups as well as for $c l b A, c l b Q$, cnf1, cif and $c d t$ genes.

\section{Cell culture assay for colibactin cytotoxicity}

The cytotoxicity assay was performed as described previously with modifications $[12,16]$. HeLa S3 cells (ATCC CCL2.2) were grown and maintained in Eagle's Minimum Essential Medium (EMEM, ATCC) containing 10\% Fetal Calf Serum (FCS, Sigma) and 1\% antibiotic-antimycotic (Gibco) at $37{ }^{\circ} \mathrm{C}$ with $5 \% \mathrm{CO}_{2} .5 \times 10^{3}$ cells were seeded onto 96-well cell culture plates and incubated at $37{ }^{\circ} \mathrm{C}$ with $5 \% \mathrm{CO}_{2}$ for $24 \mathrm{~h}$. Overnight liquid cultures of $E$. coli strains were grown for $2 \mathrm{~h}$ at $37{ }^{\circ} \mathrm{C}$ and then adjusted to O.D. $600 \mathrm{~nm}$ in 1\% FCS EMEM media to concentrations corresponding to a multiplicity of infection (MOI; the number of bacteria per cell at the onset of infection) of 1, 5, 25 and 100, respectively. Following inoculation, plates were centrifuged at $200 \mathrm{~g}$ for $10 \mathrm{~min}$ to facilitate bacterial interaction and then incubated at $37{ }^{\circ} \mathrm{C}$ with $5 \% \mathrm{CO}_{2}$ for $4 \mathrm{~h}$. Cells were then washed with EMEM and replaced with EMEM containing 10\% FCS and $200 \mu \mathrm{g} / \mathrm{mL}$ gentamicin (Gibco). Following $72 \mathrm{~h}$ incubation, plates were stained with Diff-quick stain (Thermo Scientific). Cells were then inspected under a microscope for confluence and morphological changes. Images were captured with a Zeiss Axiovert-10 microscope using Image Pro-Plus software version 7.0 at $20 \times$ magnification.

\section{Cell culture assay for sonicate cytotoxicity}

Overnight cultures of $E$. coli strains were pelleted by centrifugation at 12,000 rpm for $5 \mathrm{~min}$. Supernatant was removed, filtered through a $0.2 \mu \mathrm{m}$ filter, and stored at $-80{ }^{\circ} \mathrm{C}$ for later use. The pellets were washed in $1 \mathrm{~mL}$ of PBS and pelleted again by centrifugation at 12,000 rpm for $5 \mathrm{~min}$. Pellets were re-suspended in $2 \mathrm{~mL}$ of PBS and then sonicated on ice using the following program: amplitude: 35; power: $7 \mathrm{~W}$; $30 \mathrm{~s}$ intervals for a total of 5 min with 1 min breaks between intervals. Sonicate samples were centrifuged at $12,000 \mathrm{rpm}$ for $10 \mathrm{~min}$ at $4{ }^{\circ} \mathrm{C}$ to remove large debris and filtered through a $0.2 \mu \mathrm{M}$ filter. Total protein was quantified using the BCA assay (Thermo Fisher Scientific). HeLa cells, $5 \times 10^{3}$ were seeded onto 96-well, cell culture plates and incubated at $37{ }^{\circ} \mathrm{C}$ with $5 \% \mathrm{CO}_{2}$ for $24 \mathrm{~h}$. Cells were treated with crude bacterial sonicate $(40 \mu \mathrm{g} / \mathrm{mL}$ total protein) or supernatant $(25 \mu \mathrm{L})$ for $72 \mathrm{~h}$. Cells were stained and microscopically 
analyzed for confluence and morphological changes, as described above.

\section{Draft genome sequencing and comparative analysis}

The draft genomes of ten representative rhesus macaque $E$. coli isolates were sequenced. Genomic DNA was isolated using the MasterPure Complete DNA and RNA Purification Kit (Epicentre, Madison, WI) following the manufacturer's protocol for bacterial cell samples. DNA libraries were prepared by the Sequencing Core at the Forsyth Institute (Cambridge, MA) using NextraXT for sequencing of $2 \times 150$ paired-end reads by Illumina MiSeq. Raw sequenced reads were decontaminated of adapter sequences and quality trimmed to a Phred quality score $(\mathrm{Q}) \geq 10$ using BBDuk from the BBMap package version 37.17 (http://sourceforge.net/projects/bbmap/). Decontaminated reads were then assembled into contigs with SPAdes followed by genome annotation with RAST, both services hosted by PATRIC [27]. Sequences encoding putative virulence factor and antibiotic-resistance genes were identified using VirulenceFinder 1.5 [28] and ResFinder 2.1 [29], both using the 90\% identity and $60 \%$ minimum length threshold parameters. Syntenic relationships of $p k s$ genes and the hemolysin-cnf1 operon between genomes were determined with SimpleSynteny [30].

\section{Results}

\section{Clinical correlates}

Evaluation of medical records did not establish an unequivocal association between $E$. coli-culture status and clinical signs. There were several animals who had experienced soft feces in the months before rectal culture, but the presence of other agents (e.g. Balantidium coli or Trichuris trichuria) or clinical conditions (e.g. gastric ulcer and Helicobacter suis gastritis) preclude definitive statements. E. coli was isolated from feces in the vast majority of cases, but $E$. coli isolates were also obtained from gingiva and surgical implants. In one E. coli positive animal, a severe eosinophilic colitis was identified via colonoscopy and histopathological evaluation in an appropriate time frame to suspect $E$. coli-associated colitis, but this animal also had immune-mediated thrombocytopenia and harbored Balantidium coli [31].

\section{Microbiological characterization of $E$. coli strains isolated from macaques}

A total of 239 E. coli isolates were cultured from 269 rectal swabs and extraintestinal sites obtained from 266 macaques. The yearly prevalence of $E$. coli in macaques was $60.7 \%$ (51 out of 84 ), $85.7 \%$ (72 out of 84 ) and $75.3 \%$ (73 out of 97) in years 2012, 2014, and 2016, respectively (Table 1). In some macaques, there were more than one isolates as determined by different colony morphology characteristics, hemolysis and API code. Forty-three $(18.0 \%)$ of $239 \mathrm{E}$. coli isolates were positive for $\beta$-hemolysis on sheep blood agar plates (Table 1). The most common API code recorded in this study was 5144572 observed in $44.8 \%$ (107 out of 239) of E. coli isolates. Other API codes assigned to the $E$. coli isolates were $1144572(11.0 \%), 5044552$ (7.5\%), 5144552 (6.9\%), $5044542(6.4 \%)$ and $5144512(4.0 \%)$. Fewer than $1 \%$ of isolates belonged to other API codes. These API codes confirm the isolates cultured were E. coli.

\section{Escherichia coli isolates from macaques encoding colibactin and CNF1}

To detect whether cytotoxic virulence factors were present in isolated E. coli, PCRs were performed with primers for the $c l b A, c l b B$ and $c l b Q$ genes of the $p k s$ island, and the cnfland cnf2 genes. Among the $239 \mathrm{E}$. coli isolates, 41 (17.2\%) were $p k s+/ c n f 1-, 19$ (7.9\%) were $p k s-/ c n f 1+$, and $31(13.0 \%)$ were $p k s+/ c n f 1+$. One hundred fortyeight (61.9\%) E. coli isolates were $p k s-/ c n f 1-$ (Table 2, Fig. 1). No $c n f 2+$ isolates were detected.

Table 2 Prevalence of pks and cnf1 genes in E. coli isolates from macaques

\begin{tabular}{lcccl}
\hline & $\mathbf{2 0 1 2}$ & $\mathbf{2 0 1 4}$ & $\mathbf{2 0 1 6}$ & Total \\
\hline$p k s+/ c n f 1-(\mathrm{A})$ & $11 / 66(16.7 \%)$ & $22 / 84(26.2 \%)$ & $8 / 89(9.0 \%)$ & $41 / 239(17.2 \%)$ \\
$p k s-/ c n f 1+(\mathrm{B})$ & $0 / 66(0.0 \%)$ & $5 / 84(6.0 \%)$ & $14 / 89(15.7 \%)$ & $19 / 239(7.9 \%)$ \\
$p k s+/ c n f 1+(\mathrm{C})$ & $7 / 66(10.6 \%)$ & $14 / 84(16.7 \%)$ & $10 / 89(11.2 \%)$ & $31 / 239(13.0 \%)$ \\
$\begin{array}{c}\text { Total pks+ } \\
(\mathrm{A}+\mathrm{C})\end{array}$ & $18 / 66(27.2 \%)$ & $36 / 84(42.9 \%)$ & $18 / 89(20.2 \%)$ & $72 / 239(30.1 \%)$ \\
$\begin{array}{c}\text { Total } \text { cnf1+ } \\
(\mathrm{B}+\mathrm{C})\end{array}$ & $7 / 66(10.6 \%)$ & $19 / 84(22.6 \%)$ & $24 / 89(27.0 \%)$ & $50 / 239(20.9 \%)$ \\
\hline
\end{tabular}

Table 1 Prevalence of $E$. coli strains isolated from macaques

\begin{tabular}{lccr}
\hline & $\mathbf{2 0 1 2}$ & $\mathbf{2 0 1 4}$ & $\mathbf{2 0 1 6}$ \\
\hline E. coli positive animals & $51 / 84(60.7 \%)$ & $72 / 85(85.7 \%)$ & $73 / 97(75.3 \%)$ \\
B-hemolytic E. coli isolates & $4 / 66(6.1 \%)$ & $16 / 84(19.0 \%)$ & $23 / 89(25.8 \%)$ \\
\hline
\end{tabular}




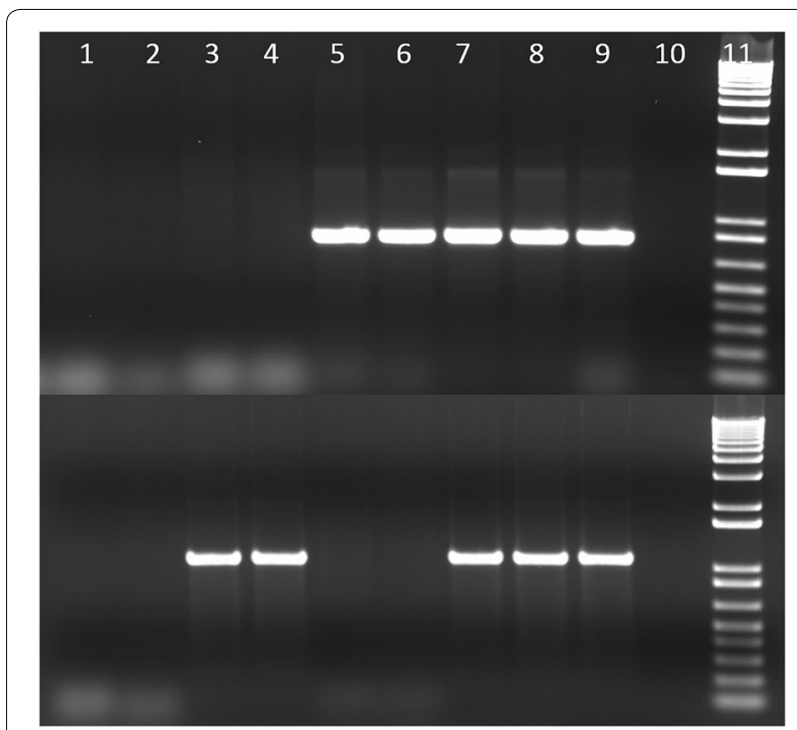

Fig. 1 Amplification of $\mathrm{clbQ}$ and $\mathrm{cnf} 1$ genes in E. coli isolates from macaques. Top row: $\mathrm{clbQ}$ gene, bottom row: $\mathrm{cnfl}$ gene. Lanes 1 and 2, S7 and S8 (pks-/cnfl-); lanes 3 and 4, S9 and S10 (pks-/cnf1+); lanes 5 and 6, S4 and S5 (pks+/cnf1-); lanes 7 and 8, S1 and S2 (pks+/cnf1+); lane 9, pks and cnf1 positive controls; lane 10, negative controls; lane 11, 1 kb+ molecular marker

Interestingly, $p k s+E$. coli strains persistently colonized 10 individual monkeys during the 5-year survey, while persistent colonization by $c n f 1+E$. coli was observed in seven macaques. There were two $E$. coli strains isolated from two rhesus; one from a cephalic recording chamber and one from the implant-margin skin site. These two $\beta$-hemolytic isolates belonged to the $\mathrm{B} 2$ group, were $p k s+/ c n f 1+$, and were identified as API code 5144572 .
Close correlation was observed between the PCR results and microbiological characteristics ( $\beta$-hemolysis and API code). Almost all (94.0\%) $\beta$-hemolytic isolates harbored the $c n f 1$ gene. API code 1144572 was related to $p k s-/ c n f 1+$ isolates, whereas $p k s+/ c n f 1-$ and $p k s+/ c n f 1+$ isolates were associated with API codes 5144572 and 5144552.

\section{Phylogenetic distribution of E. coli strains isolated from macaques}

Based on the PCR amplification pattern of multiplex PCR amplifying five genes (yjaA, TspE4.C2, chuA, svg, and uidA), the $E$. coli phylogenetic groups were defined as A, B1, B2, B2 1 , and D groups (Fig. 2). The frequency of these groups in E. coli isolates from this study (2014 and 2016) is shown in Table 3 and Fig. 3. The frequency distribution of the phylogenetic groups among the E. coli isolates was comparable between 2014 and 2016. Based on the total from 2014 to 2016 combined, the most common phylogenetic group was the B2 group (37.6\%) followed by B1 (26.0\%), B2 1 (22.5\%), A (13.3\%), and D (0.6\%).

The distribution of $p k s, c n f 1$, and $\beta$-hemolysis in E. coli strains according to phylogenetic groups is illustrated in Table 4 and Fig. 4. All $\beta$-hemolytic E. coli and all $c n f 1+E$. coli (except for one isolate) belonged to the B2 phylogenetic group. E. coli strains encoding $p k s$ genes belonged predominately to the $\mathrm{B} 2$ and $\mathrm{B} 2{ }_{1}$ groups.

\section{Serotyping}

The serotype for two $p k s+/ c n f 1+$ isolates ( $\mathrm{S} 1$ and $\mathrm{S} 2)$ was O88:H4, for five $p k s-/ c n f 1+$ isolates (S3, S6, S9, $\mathrm{S} 10$, and S11) was $\mathrm{O} 25: \mathrm{H} 4$, and for two pks+/cnf1isolates (S4 and S5) was O7:H7 (Table 5). The two $p k s-/ c n f 1-$ isolates (S7 and S8) had two different

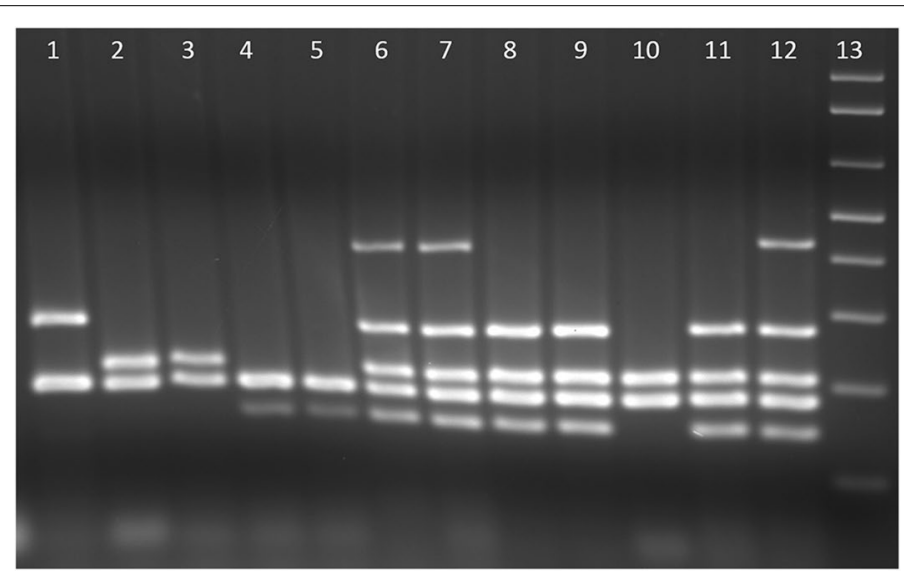

Fig. 2 Phylogenetic group determination of E. coli isolates from macaques. Lane 1, group D macaque E. coli; lanes 2 and 3, group A macaque E. coli; lanes 4 and 5, group B1 macaque E. coli; lanes 6 and 7, group B2, macaque E. coli; lanes 8 and 9, group B2 macaque E. coli; lane 10, group A control E. coli K12; lane 11, group B2 control E. coli NC101; lane 12, group B2, control E. coli RS218 (from human meningitis); lane 13, 1 kb+ molecular marker 
Table 3 Phylogenetic distribution of $E$. coli isolates from macaques

\begin{tabular}{lccl}
\hline Phylogenetic group & $\mathbf{2 0 1 4}$ & $\mathbf{2 0 1 6}$ & Total \\
\hline A & $5 / 84(6.0 \%)$ & $18 / 89(20.2 \%)$ & $23 / 173(13.3 \%)$ \\
B1 & $23 / 84(27.4 \%)$ & $22 / 89(24.7 \%)$ & $45 / 173(26.0 \%)$ \\
B2 & $37 / 84(44.0 \%)$ & $28 / 89(31.5 \%)$ & $65 / 173(37.6 \%)$ \\
B2 1 & $18 / 84(21.4 \%)$ & $21 / 89(23.6 \%)$ & $39 / 173(22.5 \%)$ \\
D & $1 / 84(1.2 \%)$ & $0 / 89(0.0 \%)$ & $1 / 173(0.6 \%)$ \\
\hline
\end{tabular}

serotypes: OM:H14 and OM:H16 (Table 5). All five $p k s-/ c n f 1+$ isolates (S3, S6, S9, S10, and S11) and both $p k s+/ c n f 1+$ isolates (S1 and S2) were confirmed positive for the $c n f 1$ gene, and none of the isolates serotyped were positive for elt, est $A$, estB, stx1, stx2, eae and $c n f 2$ genes (Table 5).
In vitro cytotoxicity of $E$. coli isolates from macaques

Previous studies have found that the cyclomodulins colibactin, CNF, CDT, and CIF cause megalocytic-like cytotoxicity to cell lines in vitro; however this effect by colibactin and CIF is dependent on contact with live bacteria, while for $\mathrm{CNF}$ and $\mathrm{CDT}$ is observable only with bacterial sonicate or supernatant treatment [11]. Therefore, we tested representative $E$. coli isolates using cell culture assays to confirm colibactin and CNF1 cytotoxic activity predicted by the PCR results.

Transient infection with $p k s+/ c n f 1-E$. coli isolates (S4, S5, and S13) at MOI 100 caused contact-dependent megalocytosis (Fig. 5a); however, sonicate treatment with these isolates did not cause observable cytotoxicity (Fig. 5b). Infection with $p k s+/ c n f 1+E$. coli isolates (S1, S2, and S14) killed all HeLa cells at MOI $\geq 5$. Surviving HeLa cells at MOI 1 appeared megalocytic (Fig. 5a). Sonicate treatment by these isolates also caused HeLa

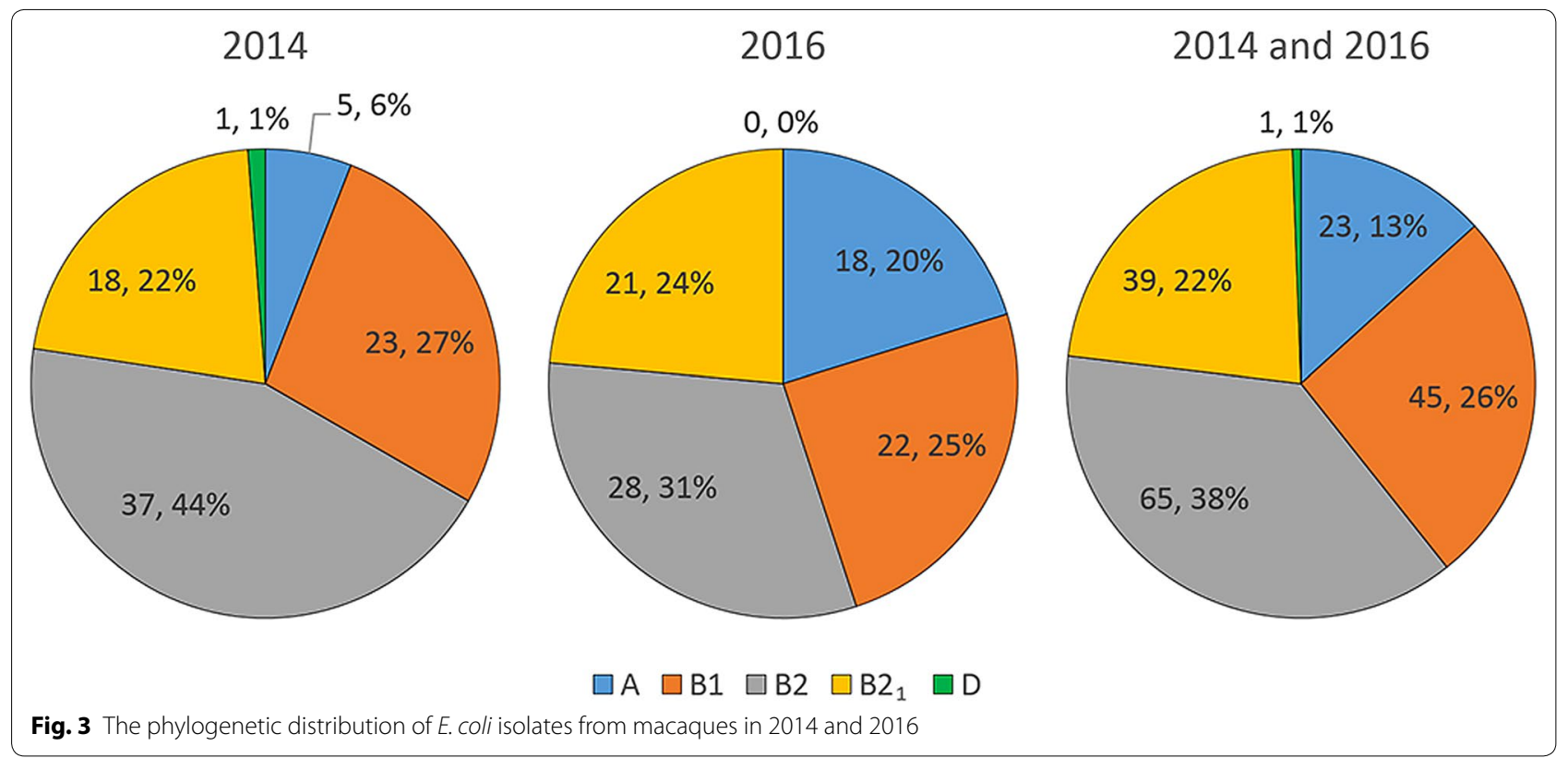

Table 4 Distribution of pks, cnf1 genes and $\beta$-hemolysis in $E$. coli isolates according to phylogenetic group

\begin{tabular}{|c|c|c|c|c|c|c|c|c|c|}
\hline \multirow{2}{*}{$\begin{array}{l}\text { Phyloge- } \\
\text { netic group }\end{array}$} & \multicolumn{3}{|l|}{ pks+ } & \multicolumn{3}{|l|}{ cnf1+ } & \multicolumn{3}{|l|}{$\beta$-hemolytic } \\
\hline & 2014 & 2016 & Total & 2014 & 2016 & Total & 2014 & 2016 & Total \\
\hline A & $0 / 36(0.0 \%)$ & 1/18 (5.6\%) & $1 / 54(1.9 \%)$ & 0/19 (0.0\%) & 0/24 (0.0\%) & 0/43 (0.0\%) & 0/16 (0.0\%) & 0/23 (0.0\%) & $0 / 39(0.0 \%)$ \\
\hline B1 & $1 / 36(2.8 \%)$ & $1 / 18(5.6 \%)$ & $2 / 54(3.7 \%)$ & 0/19 (0.0\%) & $1 / 24(4.2 \%)$ & $1 / 43(2.3 \%)$ & 0/16 (0.0\%) & 0/23 (0.0\%) & 0/39 (0.0\%) \\
\hline B2 & $33 / 36$ (91.7\%) & 11/18 (61.1\%) & $44 / 54(81.5 \%)$ & 19/19 (100\%) & $23 / 24$ (95.8\%) & $42 / 43(97.7 \%)$ & $16 / 16(100 \%)$ & 23/23 (100\%) & $39 / 39(100 \%)$ \\
\hline$B 2_{1}$ & 2/36 (5.6\%) & 5/18 (27.8\%) & 7/54 (13.0\%) & 0/19 (0.0\%) & 0/24 (0.0\%) & 0/43 (0.0\%) & 0/16 (0.0\%) & 0/23 (0.0\%) & $0 / 39(0.0 \%)$ \\
\hline D & 0/36 (0.0\%) & 0/18 (0.0\%) & $0 / 54(0.0 \%)$ & 0/19 (0.0\%) & 0/24 (0.0\%) & 0/43 (0.0\%) & 0/16 (0.0\%) & 0/23 (0.0\%) & 0/39 (0.0\%) \\
\hline
\end{tabular}




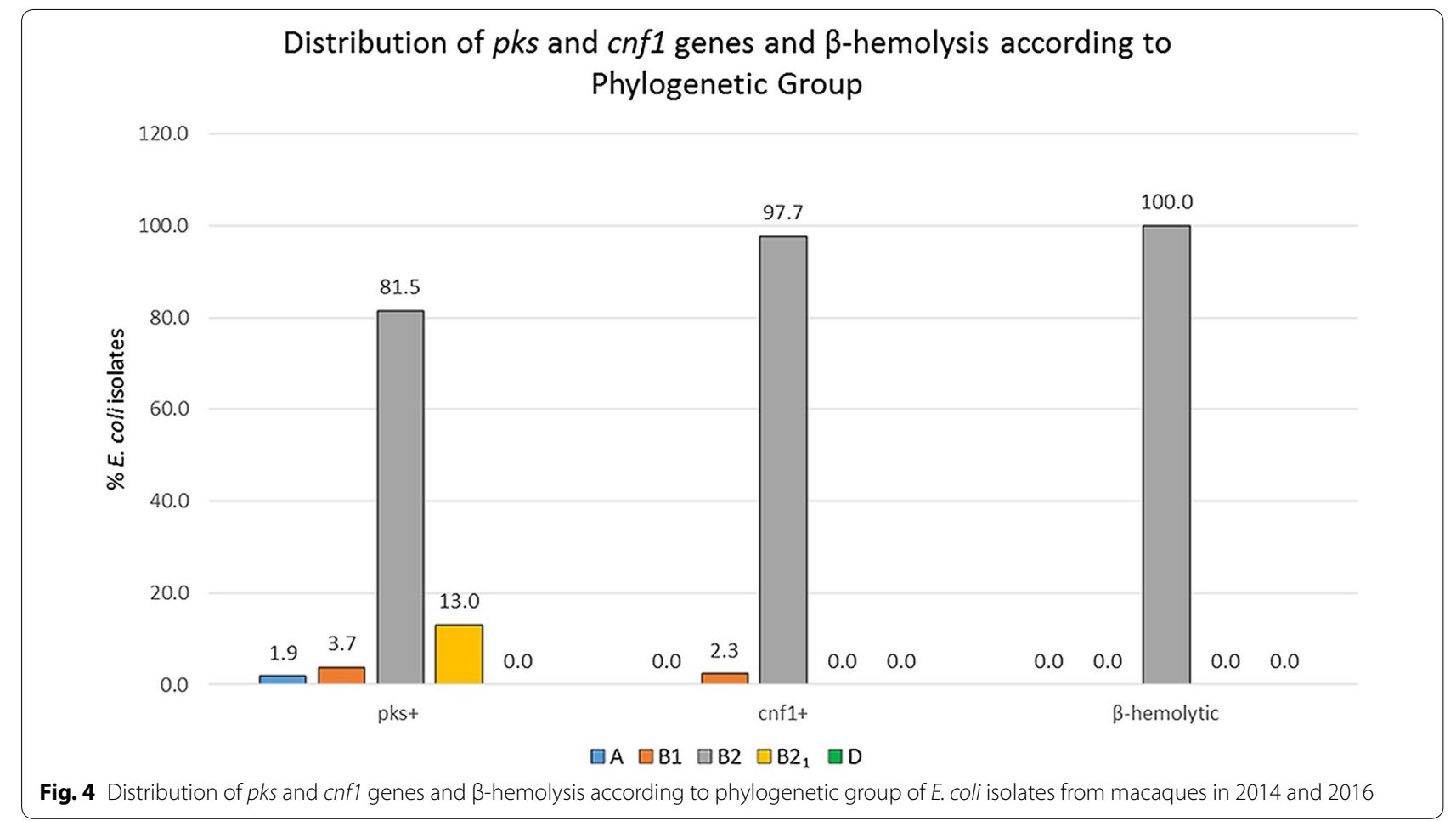

Table 5 Serotype and virulence factors testing results of $E$. coli isolates from macaques

\begin{tabular}{|c|c|c|c|c|c|c|c|c|c|c|}
\hline Sample \# & O type & $\mathrm{H}$ type & elt & est $A$ & est $B$ & stx 1 & stx2 & eae & cnf1 & cnf2 \\
\hline S1 (pks+/cnfl+) & 88 & 4 & NEG & NEG & NEG & NEG & NEG & NEG & POS & NEG \\
\hline S2 (pks+/cnfl+) & 88 & 4 & NEG & NEG & NEG & NEG & NEG & NEG & POS & NEG \\
\hline S3 (pks-/cnfl+) & 25 & 4 & NEG & NEG & NEG & NEG & NEG & NEG & POS & NEG \\
\hline S6 (pks-/cnfl+) & 25 & 4 & NEG & NEG & NEG & NEG & NEG & NEG & POS & NEG \\
\hline S9 (pks-/cnfl+) & 25 & 4 & NEG & NEG & NEG & NEG & NEG & NEG & POS & NEG \\
\hline $\mathrm{S} 10$ (pks-/cnfl+) & 25 & 4 & NEG & NEG & NEG & NEG & NEG & NEG & POS & NEG \\
\hline $\mathrm{S} 11$ (pks-/cnf1+) & 25 & 4 & NEG & NEG & NEG & NEG & NEG & NEG & POS & NEG \\
\hline S4 (pks+/cnfl-) & 7 & 7 & NEG & NEG & NEG & NEG & NEG & NEG & NEG & NEG \\
\hline S5 (pks+/cnfl-) & 7 & 7 & NEG & NEG & NEG & NEG & NEG & NEG & NEG & NEG \\
\hline S7 (pks-/cnfl-) & M & 14 & NEG & NEG & NEG & NEG & NEG & NEG & NEG & NEG \\
\hline S8 (pks-/cnfl-) & $M$ & 16 & NEG & NEG & NEG & NEG & NEG & NEG & NEG & NEG \\
\hline
\end{tabular}

cell body distention and multi-nucleation (Fig. 5b). E. coli isolates that were $p k s-/ c n f 1+(\mathrm{S} 3, \mathrm{~S} 9$, and S10) did not cause megalocytosis to HeLa cells after infection, but instead caused a cytotoxic effect observed as cellular elongation (Fig. 5a). Sonicate treatment with these isolates caused HeLa cells to become distended with multiple nuclei (Fig. 5b). HeLa cells treated with live bacteria or sonicate from $p k s-/ c n f 1-(\mathrm{S} 7, \mathrm{~S} 8$, and S12) appeared indistinguishable from those treated with media, K12, and NC101 $\Delta$ pks negative controls (Fig. 5). Megalocytic CNF1 cytotoxicity was also observed only when
HeLa cells were treated with culture supernatant from the $c n f 1+$ isolates (S3 and S14) (Additional file 2: Figure $\mathrm{S} 1$ ). All isolates were found by PCR to be negative for $c d t$ and cif genes, therefore excluding the influence of these cyclomodulins. Together, these results demonstrate that the novel E. coli isolates exhibit colibactin and CNF1 cytotoxicity, as predicted by their genotype.

\section{Draft genome sequencing and comparative analysis}

The draft genomes of ten representative rhesus macaque $E$. coli isolates were sequenced for identification of 


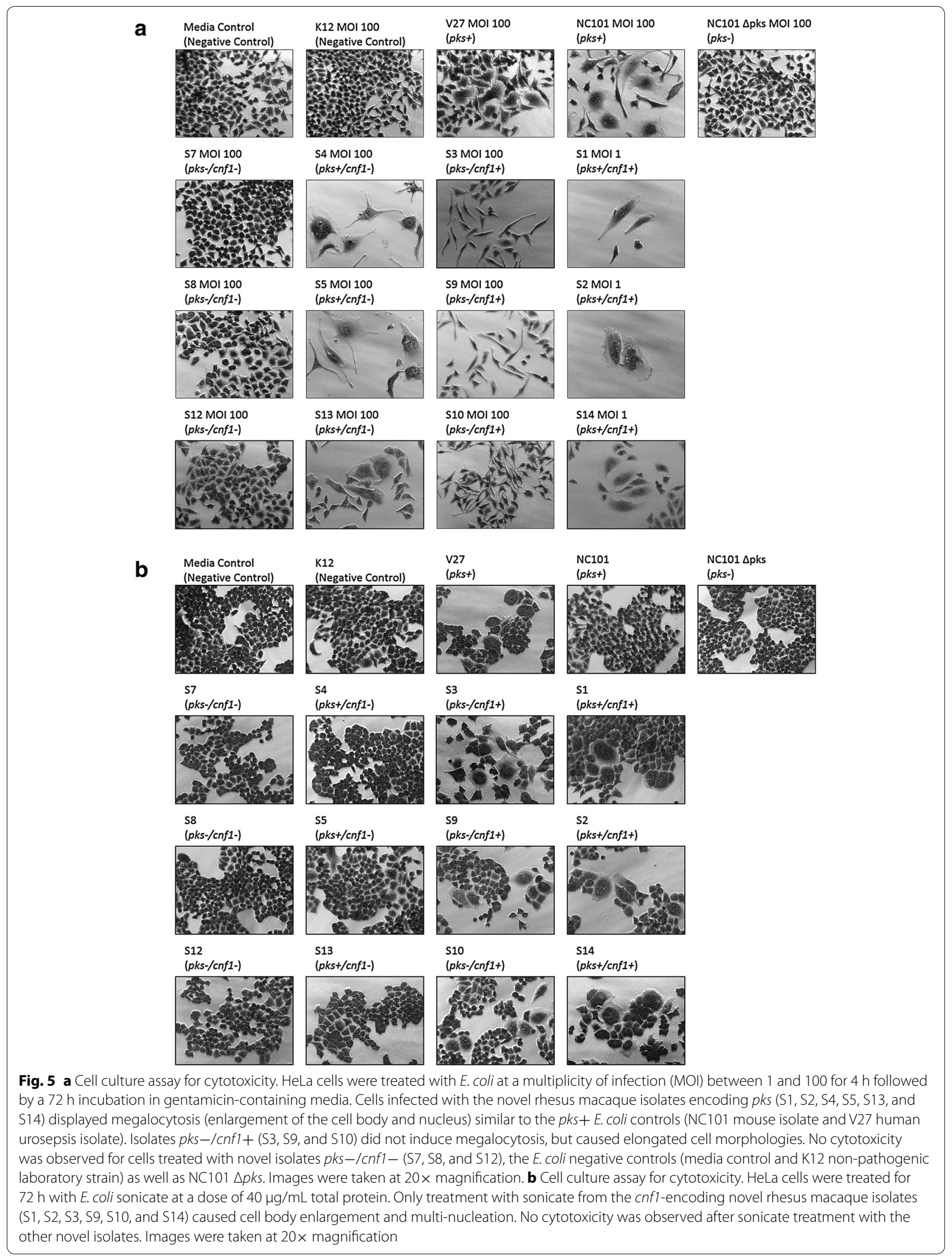


virulence factor and antimicrobial resistance genes, as well as for comparative analysis. Genome sizes, GC content, and the number of annotated protein coding and RNA genes were comparable between the different rhesus macaque $E$. coli isolates and representative pathogenic and non-pathogenic E. coli strains (Table 6).

Escherichia coli isolates that were PCR-positive for $p k s$ and/or cnf1 genes also had the full-length gene sequences detected in their annotated genomes. Additionally, sequences for the cyclomodulins $c n f 2, c d t$, and cif, as well as the virulence factor genes elt, est $A$, est $B$, stx 1 , stx 2 , and eae were not detected in any of the genomes, which agrees with previous PCR and serotyping results.

Complete $p k s$ gene islands were identified in isolates S1, S2, S4, and S5. All pks island genes showed $\geq 98 \%$ sequence homology and identical syntenic relationships compared to prototype $p k s+$ strains IHE3034 and NC101 (Fig. 6a). Likewise, all isolates positive for $c n f 1$ had the $\beta$-hemolysin genes hlyCABD immediately upstream, consistent with the hemolysin-cnf1 operon found in uropathogenic E. coli (UPEC) such as UTI89 (Fig. 6b).

Other putative virulence factor genes were also detected in the E. coli isolates (Table 6). These virulence factor genes represent toxins (astA, pic, vat, sat), survival and immune evasion factors ( $\mathrm{gad}$, iss), iron acquisition (iroN), adherence (iha, lpfA) and bacteriocin synthesis (celb, $m c h B, m c h C, m c h F, m c m A$ ). These virulence genes are associated with host colonization and pathogenicity in intestinal and extra-intestinal diseases (Additional file 1: Table S2).

\section{Discussion}

Escherichia coli is a normal inhabitant of the gastrointestinal tract of macaques and several different serotypes of bacteria have been isolated from asymptomatic rhesus macaques [32]. To our knowledge this is the first reported isolation of colibactin-encoding $E$. coli strains from macaques. Colibactin was first identified in several $E$. coli strains by Oswald and co-workers in 2006 [12]. Colibactin, encoded by a $54 \mathrm{~kb}$ gene cluster (the $p k s$ island), is a genotoxin which causes DNA double strand breaks and activation of the DNA damage checkpoint pathway, leading to cell cycle arrest and eventually cell death. The role of colibactin-encoding $E$. coli has been explored in human colorectal cancer and investigated in different types of mouse models including $\mathrm{IL} 10^{-/-}$mice treated with azoxymethane (AOM), C57BL/6J-ApcMin/J mice treated with AOM and dextran sodium sulfate (DSS), and nude mice with xenografts $[11,15,33,34]$. These studies have established a role of $p k s$-encoding E. coli in inflammation and cancer. The increase in $E$. coli growth and colonization may be due to inflammation-generated nitrate, as E. coli, a facultative anaerobe, can produce energy through the use of nitrate, $\mathrm{S}$-oxides and $\mathrm{N}$-oxides as terminal electron acceptors for anaerobic respiration and thus outcompete obligate anaerobes, the major colonizers of the lower bowel [35].

Among the $E$. coli isolates from macaques, $30.1 \%$ of isolates were $p k s+$ strains and colibactin activities were confirmed in selected isolates. The prevalence of $p k s+$ E. coli colonization in macaques was similar to the $25 \%$ prevalence of $p k s+\mathrm{B} 2 \mathrm{E}$. coli colonization in humans [36]. Several publications have revealed the higher prevalence of $p k s+E$. coli strains in biopsies from colorectal cancer (CRC) patients $(66.7 \%$ in CRC patients, $40 \%$ in IBD patients and $20.8 \%$ in no IBD/no CRC controls) [11, $15,37]$.

The $20.9 \%$ prevalence of $c n f 1+E$. coli in this study was consistent with our previous findings [21]. Close correlation was observed between the $\operatorname{cnf} 1$ gene and $\beta$-hemolysis in $E$. coli isolates. This association was reported in our previous studies [20, 21] and by other authors [19, 38]. In the E. coli $J 96$ strain and other strains, the $c n f 1$ gene is located downstream of hemolysin (hlyCABD) in pathogenicity island II (PAI II), and the expression of $c n f 1$ is regulated by the hemolysin promoter [39-41]. Likewise, our draft genome sequences of macaque $E$. coli strains indicate that hemolysin $(h l y C A B D)$ is located directly upstream of the cnfl gene. These two toxins could therefore be associated with enhanced virulence. In our in vitro cytotoxicity assays, infection with the $p k s-/ c n f 1+$ isolates (S3, S9, S10) caused $~ 50 \%$ of HeLa cells to die, and the surviving cells exhibited an elongated morphology; CNF1 cytotoxicity by these isolates was only observed with sonicate and supernatant treatment. The draft genome sequence data showed that only $p k s-/ c n f 1+$ isolates (S3, S6, S9, and S10) also contained an annotated secreted autotransporter toxin (sat), which is expressed by some UPEC strains and reported to cause cell elongation in vitro [42]. We speculate that expression of sat by these isolates may have caused HeLa cells to adopt an elongated morphology. Interestingly, we also identified E. coli strains co-harboring the $p k s$ and cnf1 genes. Thirty-one $(13.0 \%) E$. coli isolates were positive for both $p k s$ and cnfl ( $p k s+/ c n f 1+)$. The E. coli strains co-harboring these two toxins have also been reported in human samples $[10,11]$. The authors noted that $15 \%$ of $E$. coli isolates from urosepsis patients and from the feces of healthy individuals were double-positive for $p k s$ and $c n f 1$ $(p k s+/ c n f 1+)$. In our in vitro cytotoxicity assays, the isolates $p k s+/ c n f 1+(\mathrm{S} 1, \mathrm{~S} 2$, and S14) exhibited severe toxicity to HeLa cells, given all cells were dead when treated with these live isolates at MOI 5, 25 and 100 (Fig. 5).

Yasuda and co-workers characterized biogeographic relationships in the rhesus macaque intestinal microbiome and found that stool microbiota was highly 


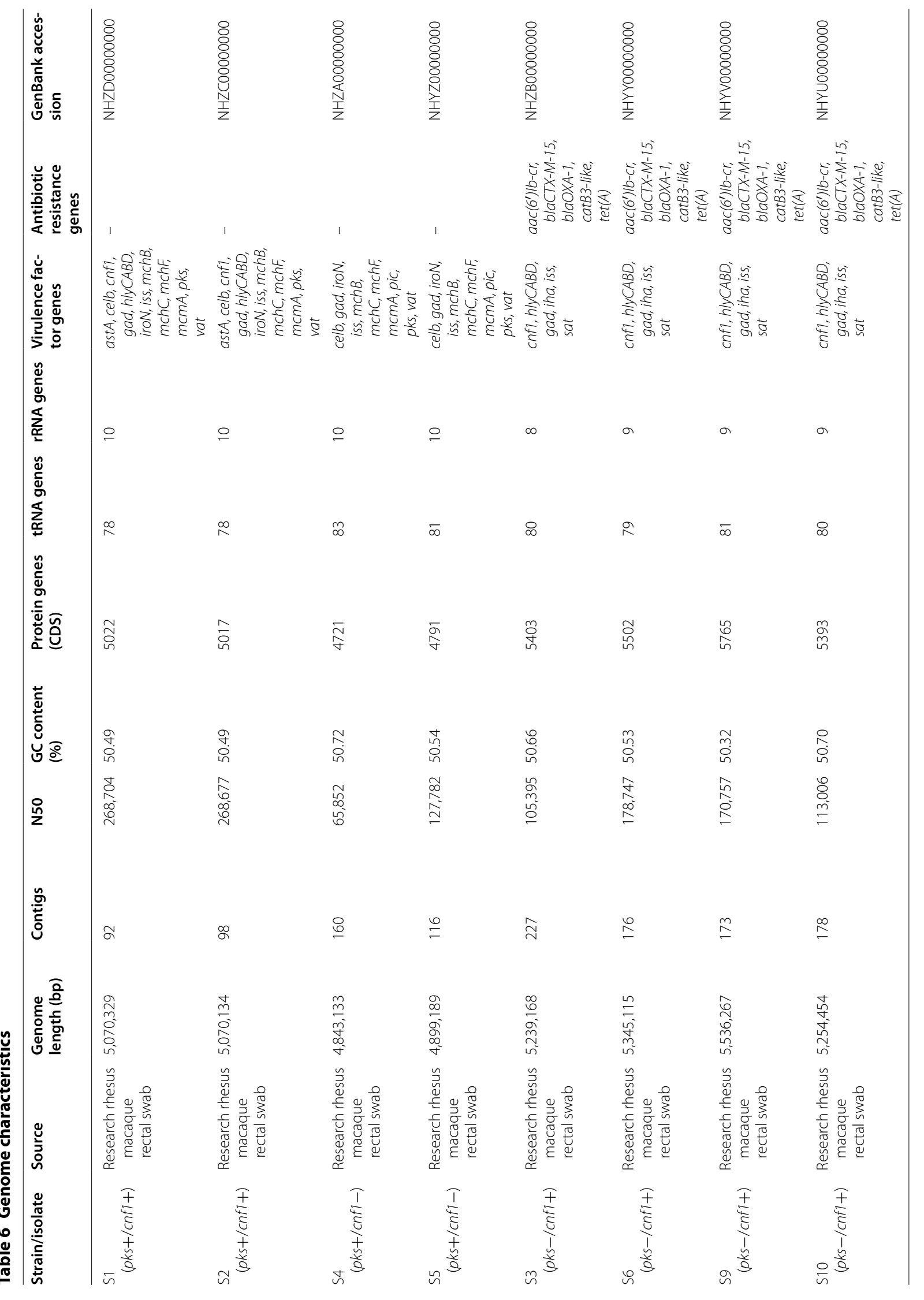




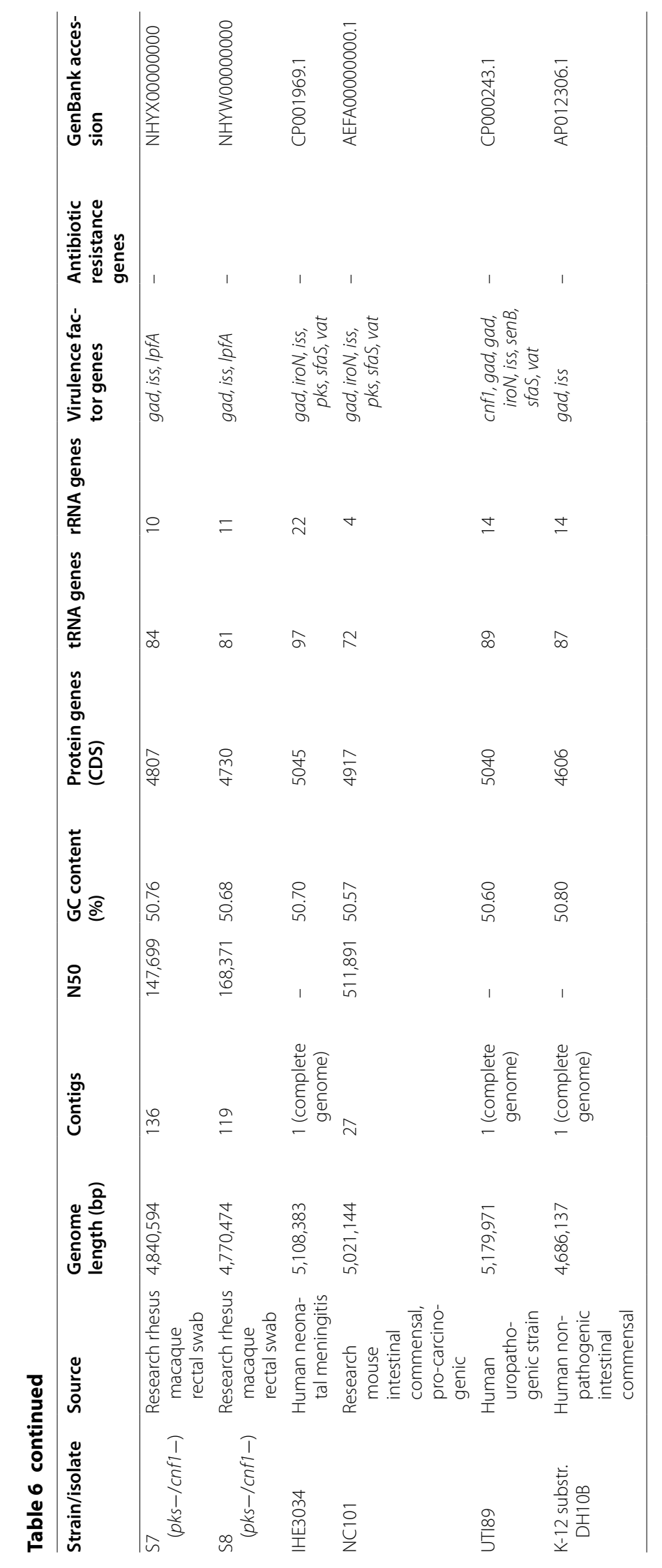




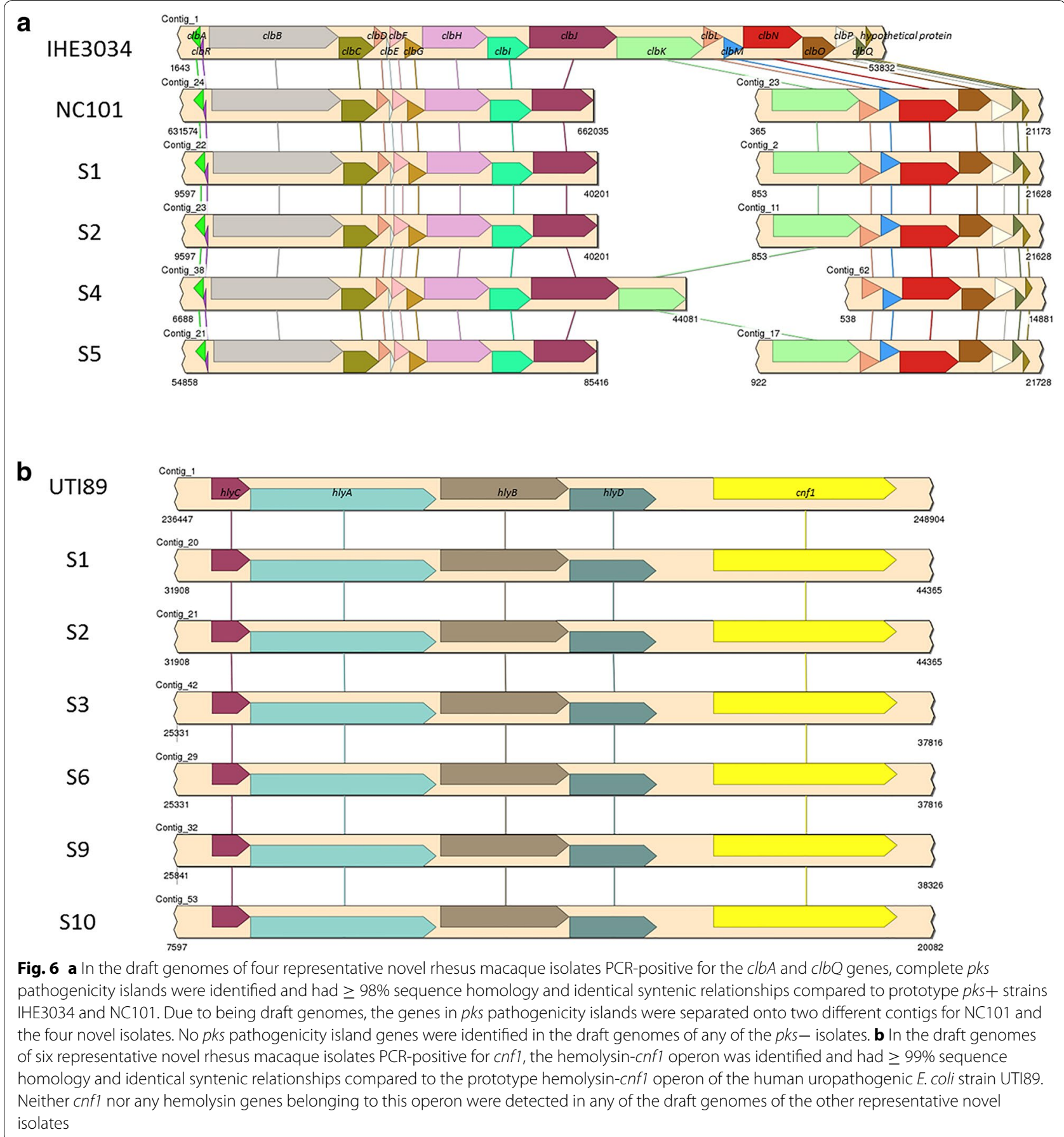

representative of the colonic lumen and mucosa, which were respectively enriched in obligate and facultative anaerobes [43]. In our study the E. coli strains were isolated from rectal swab samples and may, by analogy, be representative of the $E$. coli strains colonized in the macaque gastrointestinal tract. Moreover, among $E$. coli isolates in the present study, two isolates which were $\beta$-hemolytic and $p k s+/ c n f 1+$ were isolated from a cephalic recording chamber and implant-margin skin of two macaques. This raises the concern that these E. coli isolates may cause meningitis in macaques used in neurobiological research based on the previous reports that $p k s+E$. coli were isolated and related to meningitis in humans and animals [44]. 
For the $E$. coli isolates from macaques in this study, the predominant phylogenetic group was B2 group including B2 1 subgroup (60.1\%) followed by B1 (26.0\%), A (13.3\%), and D group $(0.6 \%)$. The distribution of phylogenetic groups of macaque $E$. coli strains were similar to distribution of $E$. coli isolates from healthy humans $[10,11]$. The distribution of cyclomodulin-encoding genes ( $p k s, c n f$, $c d t$ and cif) in relation to the phylogenetic background in $E$. coli isolates from urosepsis patients and healthy individuals indicated that strains $p k s+$ and/or $c n f 1+$ strongly associated with the B2 group [10]. In another study, the prevalence of $E$. coli producing cyclomodulins and genotoxins in colon cancer had a higher prevalence of the B2 phylogenetic group $E$. coli harboring the $p k s$ gene (55.0\%) and $c n f 1$ gene $(39.5 \%)$ in biopsies of patients with colorectal cancer than that in patients with diverticulosis $(19.3 \% p k s+$ and $12.9 \%$ cnf1+) [11]. In both studies, the percentage of $E$. coli strains harboring $c d t$ and cif genes were much lower (1-6\%). Representative isolates in our study were negative for $c d t$ and cif according to PCR, in vitro cytotoxicity assay, and genome analysis results. We found that $p k s+, c n f 1+$, and $\beta$-hemolytic $E$. coli strains belonged to group B2. 49.0\% (51 out of 104) of the isolates belonging to $\mathrm{B} 2$ (including the $\mathrm{B} 2{ }_{1}$ subgroup) were $p k s+, 40.4 \%$ (42 out of 104) were $c n f 1+$, and $37.5 \%$ (39 out of 104) were $\beta$-hemolytic. Seven $p k s+E$. coli isolates belonged to the B2 1 subgroup, which is a highly virulent phylogenetic subgroup among extra-intestinal pathogenic E. coli B2 strains [7, 44].

The serotype data in the present study revealed that the serotype of selected $E$. coli strains corresponded to their toxin-harboring content. Of the isolates serotyped, those $p k s+/ c n f 1+(\mathrm{S} 1$ and $\mathrm{S} 2)$ were the O88:H4 serotype. The pks-/cnf1+ isolates (S3, S6, S9, S10, S11) were O25:H4, the $p k s+/ c n f 1-$ isolates (S4 and S5) were O7:H7, the pks-/cnf1- isolates (S7 and S8) were OM:H14 or OM:H16. The O7:H7:K1 serotype belonging to phylogenetic group B2 was cultured from IL $10^{-/-}$and wild-type mice [45]. In these experiments, cecal and colonic inflammation observed in IL10 $0^{-/-}$mice was accompanied by diminished intestinal microbial diversity and a higher number of $E$. coli organisms compared to wild-type mice [45]. Serotype O7:H7 E. coli strains were also found among Shiga-toxin-producing E. coli strain isolated from calves in Brazil [46]. UPEC O25:H4 strains were reported in patients with urinary tract infection [47] and patients with cystitis or prostatitis [48]. These strains belonging to group B2 had multiple antibiotic drug resistance. By analyzing the draft genome sequences of our macaque $E$. coli isolates, putative multi-antibiotic resistance genes were identified exclusively in $c n f 1+$ strains (serotype O25:H4). These included resistance genes to the tetracycline $(\operatorname{tet}(A))$, phenicol (catB3-like), fluoroquinolone and aminoglycoside $\left(\operatorname{aac}\left(6^{\prime} 6^{\prime}\right) \mathrm{Ib}-\mathrm{cr}\right)$, and $\beta$-lactam (blaCTX$M-15$, blaOXA-1) classes of antibiotics, consistent with our previous antibiotic resistance findings of $c n f 1+E$. coli strains in macaques [21]. Other studies have noted that antibiotic-susceptibility is inversely related to the number of virulence factor genes present in extra-intestinal $E$. coli strains [49]. Similarly, in this study isolates that were $p k s-/ c n f 1+$ had the second fewest number of virulence factor genes and also were the only isolates with putative antibiotic resistance genes detected.

Different virulence factor gene profiles appear to be present depending on whether the isolates were $p k s+/ c n f 1+, p k s+/ c n f 1-, p k s-/ c n f 1+$, or $p k s-/ c n f 1-$. The number and prolife of these virulence genes agrees with in vitro cytotoxicity to HeLa cells in that the isolates showing pronounced cytotoxicity ( $p k s+$ and/or $c n f 1+$ strains) had substantially more virulence factor genes present in their genomes compared to the less cytotoxic $p k s-/ c n f 1-$ isolates. Except for $l p f A$, the $p k s-/ c n f 1-$ $E$. coli isolates had the same virulence factor genes as $\mathrm{K} 12$, suggesting that along with the in vitro cytotoxicity results, these isolates likely have attenuated pathogenic potential. Interestingly, $p k s+$ strains harboring the bacteriocin synthesis genes for colicin E2 and microcin H47 also had the most virulence genes. This agrees with other studies reporting that $E$. coli strains expressing bacteriocins are statistically more likely to co-associate with more virulence factor genes in their genomes compared to strains that lack bacteriocin potential [49-51]. Likewise, bacteriocin genes are found more frequently in $E$. coli strains belonging to the pathogenic B2 or D phylogroup, such as our monkey isolates [49, 50, 52]. In particular, microcin $\mathrm{H} 47$ is predominantly found in the UPEC strains [53]. It is hypothesized that bacteriocin activity by pathogenic E. coli may provide a competitive survival and colonization advantage against commensal organisms, especially when availability of essential nutrients, like iron, is scarce [51].

In summary, E. coli strains encoding colibactin, CNF1, or both were identified in macaques. The $p k s+$ and/ or $c n f 1+$ isolates belonged to phylogenetic group B2 and induced cytotoxic effects to HeLa cells in vitro. The genomic data supports the presence of virulence factor and antibiotic resistance genes in these isolates and suggests that they may have the pathogenic potential to influence clinical and subclinical disease. The impact of these strains on the health of macaques is unclear as analysis of medical records did not allow an association of clinical events and isolation of E. coli. Given colibactin and CNF1-encoding $E$. coli has been isolated from human and animals populations, there is a concern about potential zoonotic spread. The presence of colibactin and CNF1-producing E. coli strains in primates used in 
neurobiology emphasizes the importance of appropriate personnel protection and hygiene practices when handling these primates.

\section{Conclusions}

The prevalence of $p k s+E$. coli in rhesus macaques is not known, nor is there published evidence that $E$. coli strains encoding both $p k s$ and $c n f 1$ genes colonize macaques. In the present study, E. coli strains encoding colibactin and CNF1 were identified in the rectal swabs and extraintestinal samples of macaques sampled over a 3-year period. Among the 239 isolates, $72(30.1 \%)$ were positive for $p k s$ genes and $50(20.9 \%)$ were cnf1+. Our findings indicate that colibactin and CNF1-encoding E. coli colonizing laboratory macaques can potentially cause clinical and subclinical diseases that impact studies conducted in macaque models.

\section{Additional files}

Additional file 1: Table S1. Genes, primers, and annealing temperature used for amplification. Table S2. Virulence genes.

Additional file 2: Figure S1. Only treatment with supernatant from the cnf1-encoding novel rhesus macaque isolates $(\mathrm{S} 3, \mathrm{~S} 14)$ caused cell body enlargement and multi-nucleation. No cytotoxicity was observed after supernatant treatment with the other novel isolates. Images were taken at $20 \times$ magnification.

\section{Authors' contributions}

YF performed PCR, cell cultures, assisted in data analysis, and was a major contributor in writing the manuscript. AM performed genome sequencing and comparative analysis, cell culture assays, assisted in data analysis, and was a major contributor in writing the manuscript. CMM performed bacterial culture, isolation, and identification, as well as data management. AGS collected samples, assisted in bacterial culture, DNA extraction, and PCR, as well as data interpretation. CT assisted with statistical analyses by evaluating data from an NHP survey of pks + E. coli samples collected from the colonies at MIT, assisted in bacterial culture, DNA extraction, and PCR. CB assisted in bacterial culture, DNA extraction, and PCR. RPM analyzed medical records for survey, assisted in project oversight, and contributed to writing the manuscript. JGF was responsible for project conception and design, provided project oversight, data interpretation and analysis, and was a major contributor in writing the manuscript. All authors read and approved the final manuscript.

\section{Author details}

${ }_{1}^{1}$ Division of Comparative Medicine, Massachusetts Institute of Technology, 77 Massachusetts Avenue, 16-825, Cambridge, MA 02139, USA. ${ }^{2}$ Present Address: Center for Comparative Medicine, Baylor College of Medicine, Houston, TX, USA. ${ }^{3}$ Present Address: North Powers Animal Hospital, Colorado Springs, CO, USA.

\section{Acknowledgements}

We would like to thank Alyssa Pappa for her excellent assistance preparing the manuscript.

\section{Competing interests}

The authors declare that they have no competing interests.

\section{Consent for publication}

Not applicable.
Data availability

Please contact corresponding author (James G. Fox) for data requests.

\section{Ethics approval and consent to participate}

Work involving animals was approved by the Massachusetts Institute of Technology's Committee on Animal Care and Use Office.

\section{Funding}

Research reported in this publication was supported by The National Institutes of Health under Award Numbers T32OD010978, R01CA093405, P01CA02884223 and National Institute of Environmental Health Sciences under Award P30ES0022109. The content is solely the responsibility of the authors and does not necessarily represent the official views of the National Institutes of Health.

\section{Publisher's Note}

Springer Nature remains neutral with regard to jurisdictional claims in published maps and institutional affiliations.

Received: 20 October 2017 Accepted: 21 November 2017

Published online: 06 December 2017

\section{References}

1. Leser TD, Molbak L. Better living through microbial action: the benefits of the mammalian gastrointestinal microbiota on the host. Environ Microbiol. 2009;11(9):2194-206.

2. Kaper JB, Nataro JP, Mobley HL. Pathogenic Escherichia coli. Nat Rev Microbiol. 2004;2(2):123-40.

3. Croxen MA, Finlay BB. Molecular mechanisms of Escherichia coli pathogenicity. Nat Rev Microbiol. 2010;8(1):26-38.

4. Clermont O, Bonacorsi S, Bingen E. Rapid and simple determination of the Escherichia coli phylogenetic group. Appl Environ Microbiol. 2000;66(10):4555-8.

5. Herzer PJ, et al. Phylogenetic distribution of branched RNA-linked multicopy single-stranded DNA among natural isolates of Escherichia coli. J Bacteriol. 1990;172(11):6175-81.

6. Carlos C, et al. Escherichia coli phylogenetic group determination and its application in the identification of the major animal source of fecal contamination. BMC Microbiol. 2010;10:161.

7. Bidet $P$, et al. Detection and identification by $P C R$ of a highly virulent phylogenetic subgroup among extraintestinal pathogenic Escherichia coli B2 strains. Appl Environ Microbiol. 2007;73(7):2373-7.

8. Picard B, et al. The link between phylogeny and virulence in Escherichia coli extraintestinal infection. Infect Immun. 1999;67(2):546-53.

9. Escobar-Paramo P, et al. Identification of forces shaping the commensal Escherichia coli genetic structure by comparing animal and human isolates. Environ Microbiol. 2006;8(11):1975-84.

10. Dubois D, et al. Cyclomodulins in urosepsis strains of Escherichia coli. J Clin Microbiol. 2010;48(6):2122-9.

11. Buc E, et al. High prevalence of mucosa-associated E. coli producing cyclomodulin and genotoxin in colon cancer. PLOS ONE. 2013;8(2):e56964.

12. Nougayrede JP, et al. Escherichia coli induces DNA double-strand breaks in eukaryotic cells. Science. 2006;313(5788):848-51.

13. Putze J, et al. Genetic structure and distribution of the colibactin genomic island among members of the family Enterobacteriaceae. Infect Immun. 2009;77(11):4696-703.

14. Kim SC, et al. Variable phenotypes of enterocolitis in interleukin 10-deficient mice monoassociated with two different commensal bacteria. Gastroenterology. 2005;128(4):891-906.

15. Arthur JC, et al. Intestinal inflammation targets cancer-inducing activity of the microbiota. Science. 2012;338(6103):120-3.

16. Garcia A, et al. Cytotoxic Escherichia coli strains encoding colibactin colonize laboratory mice. Microbes Infect. 2016;18(12):777-86.

17. Falbo V, et al. Isolation and nucleotide sequence of the gene encoding cytotoxic necrotizing factor 1 of Escherichia coli. Infect Immun. 1993;61(11):4909-14. 
18. Oswald E, et al. Cytotoxic effect of multinucleation in HeLa cell cultures associated with the presence of Vir plasmid in Escherichia coli strains. FEMS Microbiol Lett. 1989;49(1):95-9.

19. Landraud $L$, et al. Frequency of Escherichia coli strains producing the cytotoxic necrotizing factor (CNF1) in nosocomial urinary tract infections. Lett Appl Microbiol. 2000;30(3):213-6.

20. Marini RP, et al. Characterization of hemolytic Escherichia coli strains in ferrets: recognition of candidate virulence factor CNF1. J Clin Microbiol. 2004;42(12):5904-8.

21. Martin HR, et al. Characterization of cytotoxic necrotizing factor 1-producing Escherichia coli strains from faeces of healthy macaques. J Med Microbiol. 2009;58(Pt 10):1354-8.

22. Feria $\mathrm{C}$, et al. Virulence genes and P fimbriae PapA subunit diversity in canine and feline uropathogenic Escherichia coli. Vet Microbiol. 2001;82(1):81-9.

23. Johnson JR, et al. Identification of urovirulence traits in Escherichia coli by comparison of urinary and rectal E. coli isolates from dogs with urinary tract infection. J Clin Microbiol. 2003;41(1):337-45.

24. Siqueira AK, et al. Virulence factors in Escherichia coli strains isolated from urinary tract infection and pyometra cases and from feces of healthy dogs. Res Vet Sci. 2009;86(2):206-10.

25. Toth I, et al. Characterization of intestinal cnf1+ Escherichia coli from weaned pigs. Int J Med Microbiol. 2000;290(6):539-42.

26. Rodriguez-Siek KE, et al. Comparison of Escherichia coli isolates implicated in human urinary tract infection and avian colibacillosis. Microbiology. 2005;151(Pt 6):2097-110.

27. Wattam AR, et al. Improvements to PATRIC, the all-bacterial bioinformatics database and analysis resource center. Nucleic Acids Res. 2017:45(D1):D535-42.

28. Joensen $\mathrm{KG}$, et al. Real-time whole-genome sequencing for routine typing, surveillance, and outbreak detection of verotoxigenic Escherichia coli. J Clin Microbiol. 2014;52(5):1501-10.

29. Zankari $\mathrm{E}$, et al. Identification of acquired antimicrobial resistance genes. J Antimicrob Chemother. 2012;67(11):2640-4.

30. Veltri D, Wight MM, Crouch JA. SimpleSynteny: a web-based tool for visualization of microsynteny across multiple species. Nucleic Acids Res. 2016;44(W1):W41-5.

31. Frydman GH, et al. Local and systemic changes associated with longterm, percutaneous, static implantation of titanium alloys in rhesus macaques (Macaca mulatta). Comp Med. 2017;67(2):165-75.

32. Schiff $L$, et al. Enteropathogenic Escherichia coli infections: increasing awareness of a problem in laboratory animals. Lab Anim Sci. 1972;22(5):705-8.

33. Cougnoux A, et al. Bacterial genotoxin colibactin promotes colon tumour growth by inducing a senescence-associated secretory phenotype. Gut. 2014;63(12):1932-42.

34. Bonnet $\mathrm{M}$, et al. Colonization of the human gut by E. coli and colorectal cancer risk. Clin Cancer Res. 2014;20(4):859-67.

35. Winter $\mathrm{SE}$, et al. Host-derived nitrate boosts growth of E. coli in the inflamed gut. Science. 2013;339(6120):708-11.

36. Secher T, Brehin C, Oswald E. Early settlers: which E. coli strains do you not want at birth? Am J Physiol Gastrointest Liver Physiol. 2016;311(1):G123-9.
37. Raisch J, et al. Colon cancer-associated B2 Escherichia coli colonize gut mucosa and promote cell proliferation. World J Gastroenterol. 2014;20(21):6560-72.

38. Blanco M, et al. Polymerase chain reaction for detection of Escherichia coli strains producing cytotoxic necrotizing factor type 1 and type 2 (CNF1 and CNF2). J Microbiol Methods. 1996;26(1):95-101.

39. Blum $\mathrm{G}$, et al. Gene clusters encoding the cytotoxic necrotizing factor type 1, Prs-fimbriae and alpha-hemolysin form the pathogenicity island II of the uropathogenic Escherichia coli strain J96. FEMS Microbiol Lett. 1995;126(2):189-95.

40. Landraud L, et al. Expression of $\mathrm{cnf} 1$ by Escherichia coli J96 involves a large upstream DNA region including the hlyCABD operon, and is regulated by the RfaH protein. Mol Microbiol. 2003;47(6):1653-67.

41. Lemonnier M, Landraud L, Lemichez E. Rho GTPase-activating bacterial toxins: from bacterial virulence regulation to eukaryotic cell biology. FEMS Microbiol Rev. 2007;31(5):515-34.

42. Guyer DM, et al. Identification of sat, an autotransporter toxin produced by uropathogenic Escherichia coli. Mol Microbiol. 2000;38(1):53-66.

43. Yasuda K, et al. Biogeography of the intestinal mucosal and lumenal microbiome in the rhesus macaque. Cell Host Microbe. 2015;17(3):385-91.

44. Bonacorsi S, et al. Molecular analysis and experimental virulence of French and North American Escherichia coli neonatal meningitis isolates: identification of a new virulent clone. J Infect Dis. 2003;187(12):1895-906.

45. Wohlgemuth $\mathrm{S}$, et al. Reduced microbial diversity and high numbers of one single Escherichia coli strain in the intestine of colitic mice. Environ Microbiol. 2009;11(6):1562-71.

46. Aidar-Ugrinovich $\mathrm{L}$, et al. Serotypes, virulence genes, and intimin types of Shiga toxin-producing Escherichia coli (STEC) and enteropathogenic $E$. coli (EPEC) isolated from calves in Sao Paulo, Brazil. Int J Food Microbiol. 2007;115(3):297-306.

47. Molina-Lopez J, et al. Drug resistance, serotypes, and phylogenetic groups among uropathogenic Escherichia coli including O25-ST131 in Mexico City. J Infect Dev Ctries. 2011;5(12):840-9.

48. Morales-Espinosa $\mathrm{R}$, et al. UPEC strain characterization isolated from Mexican patients with recurrent urinary infections. J Infect Dev Ctries. 2016:10(4):317-28.

49. Budic M, et al. Escherichia coli bacteriocins: antimicrobial efficacy and prevalence among isolates from patients with bacteraemia. PLOS ONE. 2011;6(12):e28769.

50. Abraham S, et al. Molecular characterization of Escherichia coli strains that cause symptomatic and asymptomatic urinary tract infections. J Clin Microbiol. 2012;50(3):1027-30.

51. Micenkova $L$, et al. Bacteriocin-encoding genes and EXPEC virulence determinants are associated in human fecal Escherichia coli strains. BMC Microbiol. 2014;14:109.

52. Micenkova $L$, et al. Microcin determinants are associated with $B 2$ phylogroup of human fecal Escherichia coli isolates. Microbiologyopen. 2016;5(3):490-8.

53. Azpiroz MF, Poey ME, Lavina M. Microcins and urovirulence in Escherichia coli. Microb Pathog. 2009;47(5):274-80.

\section{Submit your next manuscript to BioMed Central and we will help you at every step:}

- We accept pre-submission inquiries

- Our selector tool helps you to find the most relevant journal

- We provide round the clock customer support

- Convenient online submission

- Thorough peer review

- Inclusion in PubMed and all major indexing services

- Maximum visibility for your research

Submit your manuscript at www.biomedcentral.com/submit 